\title{
INVESTIGATION OF RESIDENCE TIME DISTRIBUTION AND LOCAL MEAN AGE OF FLUID TO DETERMINE DEAD-ZONES IN FLOW FIELD
}

\author{
T. KARCHES \& K. BUZAS \\ Department of Sanitary and Environmental Engineering, \\ Budapest University of Technology and Economics, Hungary.
}

\begin{abstract}
Residence time and local mean age of fluid are important parameters of the fluid flow, with which we are able to detect the functioning and non-functioning zones. It is a novel approach to estimate the effect of dead-zones on chemical and biological processes. In this paper, we introduce a numerical tracer study, which is calibrated by field measurements and which is applied in different cases such as settling tank and aeration tank of wastewater treatment. Using an advective-diffusive passive scalar transport equation, the age of the fluid can be calculated. It also shows the short-circuits and dead-zones of the fluid and this corresponds with our observations. This method helps eliminate potential hydraulic problems at the early stage of design.
\end{abstract}

Keywords: CFD, dead-zone, local mean age, tracer study.

\section{INTRODUCTION}

Settling tanks in the wastewater treatment have a key role in the separation of suspended solids and sludge flocks. The design of these tanks is based on the ATV-A131 standard [1], which takes into account only the global parameters of the flow, e.g. average residence time, but in many cases the inequalities inside the tank may have serious effect on effluent quality. In this paper, we are first and foremost interested in the detection of dead-zones, where the mixing is adverse due to low velocity, high residence time and fluid age. In aeration tanks, for example, anaerobic zones may develop because microorganisms consume the oxygen. There is mass transfer between the flow and dead-zone because of the presence of turbulence; however, this is much less than the effect of convective transport. On the other hand, hydraulically inactive zones are redundant and these increase the cost of operation. Computational fluid dynamics is widely applied in wastewater treatment tank design [2-4]) because with the knowledge of hydraulic phenomena, the understanding of biochemical processes could be improved. One significant linking parameter between the hydraulics and biology is residence time; therefore, it is essential to know the precise value for every point. Residence time distribution (RTD) can be measured experimentally [5]. In pulse experiment, the tracer is mixed in a small volume of fluid, which is introduced to the reactor in a very short time interval (Dirac-delta function) and the response function is measured at the outlet. The tracer should be a conservative material without any background concentration of the wastewater. The response function shows the changes in tracer concentration in the course of time, from which we can estimate the hydraulic behavior of the tank. RTD calculations can be performed numerically, and they can be compared to the results of the field measurement.

This paper deals with circular flow reactors, one aeration tank and one radial flow settling reactor. The first is designed as a fully mixed reactor, but the RTD investigation demonstrated that there is a short-circuit, where the nutrients could flow through the reactor rapidly and did not have enough time for biodegradation. Circular radial flow settling tanks generally have problems with short-circuiting and the wind also could have an influence on the flow regimes. 
As Burt [6] also demonstrated, the weirs of final clarifier have to be appropriately designed because the flow pattern at the outlet could also have influence on settling. It requires special attention on weir outflow design because the circumstances at the outlet could react to the settling. As other scientists revealed [7,8], improper feedwell and baffle design did not break the energy efficiently and the high velocities decreased the residence time.

In order to visualize the critical zones, we can inject many particles to the flow and follow their paths, while their age can be quantified by statistical analysis. This long-lasting and uncertain procedure can be avoided if a new scalar is introduced to the model system. Local mean age (LMA) is a passive scalar, which can be calculated using the flow field. This equation derives from the convection-diffusion transport equation. As a result, high LMA zones are detected and compared with the RTD results.

The applied numerical method is described in section 2, and the two case studies are presented in section 3. Numerical results of the aeration tank calculation are verified by experimental measurements. LMA method was applied in the case of radial flow settling reactor, where two constructions were compared: one with wear outlet and the other with perforated pipe outlet.

\section{NUMERICAL METHOD}

Turbulent fluid flow can be described with the use of continuity, Navier-Stokes and turbulence closure equations [9], and each of these has a form of the conservation equation. The $\mathrm{k}-\varepsilon$ turbulence model was used for the closure of the partial differential equation system. One equation is solved for the turbulence kinetic energy $(\mathrm{k})$ and one for the turbulent dissipation $(\varepsilon)$. This approach assumes isotropic turbulence according to Launder [10].

\section{RTD experiment:}

$\mathrm{LiCl}$ was used as a tracer in the field measurement in a pulse-like initial condition. $\mathrm{LiCl}$ dilution was injected at the inlet boundary and the concentration was measured at the outlet. The response function $(\mathrm{E}(\mathrm{t}))$ was defined as the normalized concentration.

The Fluent Mixture model [11] was used for the numerical calculation, which uses massaveraged velocity for the continuity equation and sums up the individual momentum for all phases in the Navier-Stokes equation. As a scalar variable, we introduced volume fraction, which can be calculated by dividing the secondary phase volume with the total volume.

If the tracer is injected in a short time interval, small concentrations can appear at the outflow. Here, the magnitude of the rounding error is close to the detected concentration, which causes significant uncertainties in the detection. Having eliminated this, the tracer was emitted to the inflow continuously. In this case, the response function was a cumulative function of concentration, which shows how fast the original fluid was replaced by the tracer. Volume fraction is the same as in eqn (1) described as $F(t)$. Furthermore, the time derivative of $F(t)$ is equal to $\mathrm{E}(\mathrm{t})$; therefore, the field measurement and the numerical model can be compared. The Mixture model [12] uses slip velocity, which is the velocity difference between the secondary and primary phase. The particle relaxation time is low and the tracer has the same characteristics with the original fluid.

$$
\begin{gathered}
F(t)=\frac{C(t)}{C_{0}} \\
E(t)=\frac{d F(t)}{d t},
\end{gathered}
$$


where $\mathrm{C}(\mathrm{t})$ is the concentration of tracer measured at the outlet and $\mathrm{C}_{0}$ is the concentration of tracer at the inlet in a step experiment.

Average residence time is the first order momentum of $\mathrm{E}(\mathrm{t})$ :

$$
\bar{t}=\int_{0}^{\infty}(t \cdot E(t)) d t
$$

An additional convection-diffusion scalar transport equation needs to be solved for the LMA calculation:

$$
\frac{\partial \rho \varphi}{\partial t}+\nabla \cdot(\rho \vec{v} \varphi-\Gamma \nabla \varphi)=S
$$

where $\rho$ is the fluid density, $\phi$ is the LMA of the fluid, $v$ is the fluid velocity, $\Gamma$ is the diffusion coefficient and $\mathrm{S}$ is the source term of the scalar, which is equal to 1. The turbulent diffusion term is calculated by using effective turbulent viscosity:

$$
\Gamma=\frac{\mu_{e f f}}{\sigma_{S C}}
$$

where $\mu_{\text {eff }}$ is the effective turbulent viscosity and $\sigma_{\mathrm{SC}}$ is the Schmidt number, which has a constant value of 0.7. As eqn (5) shows, the diffusion term is defined on the basis of turbulent field structure [13].

Assuming steady state condition, eqn (4) can be simplified as:

$$
\nabla \cdot\left(\vec{v} \varphi-\frac{\mu_{e f f}}{\rho \sigma_{S C}} \nabla \varphi\right)=1
$$

The boundary condition for eqn (6) is zero value at the inlet and a zero gradient at the outflow boundary as Chanteloup and Mirade [14] described in their paper.

The model equations cannot be solved analytically; therefore, spatial discretization was required. Second order discretization scheme was used for all equations to reduce numerical diffusion and the Semi-Implicit Method for Pressure Linked Equations (SIMPLE) scheme was used for the pressure-velocity coupling. In each case, the finite volume method was applied and unstructured mesh was generated.

\section{RESULTS AND DISCUSSION}

\subsection{Aeration tank}

In the first case, we examined a small municipal wastewater treatment plant. It has a compact form and consists of a settling and an aeration tank (Fig. 1). Aeration tank is responsible for the reduction of organic material and the nitrification process. The produced sludge flocks are settled in the sedimentation tank. Effectiveness of aeration is essential to ensure the reduction of nutrients, but maintenance of the smoothness of oxygen distribution is not easy due to the tank design. Dead-zones may occur easily, especially where the fluid age increases and microorganisms consume the oxygen. In anaerobic zones, nutrient removal is diminished, thus resulting in poor effluent quality. 

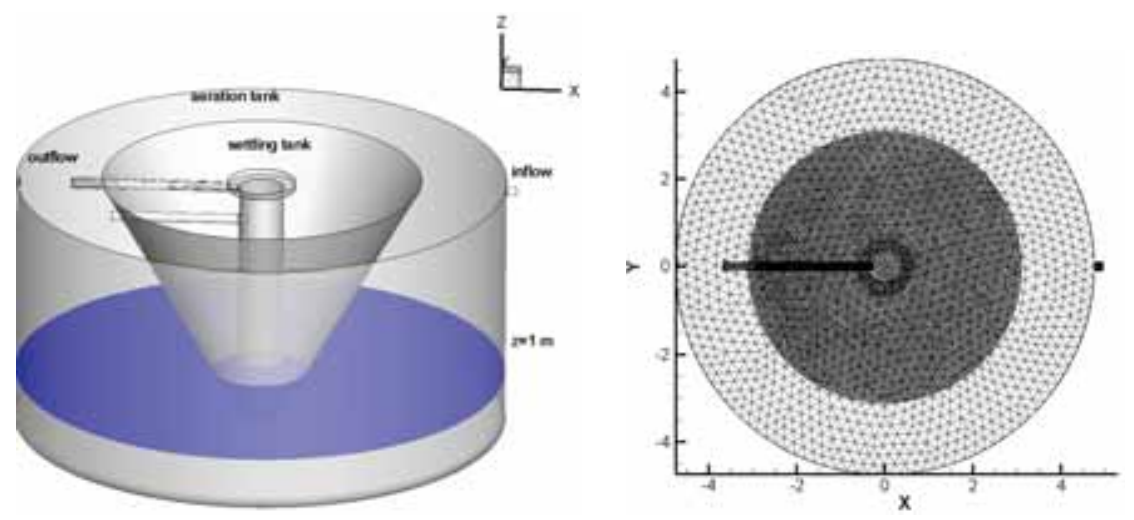

Figure 1: Aeration and settling tank geometry three-dimensional Cartesian coordinates (left) and the applied mesh in $\mathrm{z}=1 \mathrm{~m}$ cross section (right).

Here, tetrahedral mesh with size function was used for discretization. Finer mesh was required at the inflow, around the inner pipes and at the outlet boundary. Inflow boundary condition was $185 \mathrm{~m}^{3} / \mathrm{s}$ of fluid discharge due to the $85 \%$ cumulative frequency of volume flux measured. Free surface condition was set at the top and atmospheric pressure was used at the outlet. Zero fluid velocity was prescribed at the walls.

At the beginning, a steady state calculation was performed. As the solution converged, Fluent Mixture [9] model was set with two phases. The primary phase was the original wastewater, and the secondary phase was the tracer with the same boundary conditions and physical properties as the first phase. The tracer was added through the inlet section continuously. The type of modeling was changed to unsteady with time step of one second. Volume fraction of the tracer was observed at the outflow boundary by the course of time. In the field experiment, $\mathrm{LiCl}$ dilution was discharged with Dirac-delta function, the outflow concentration was measured and $\mathrm{E}(\mathrm{t})$ was obtained. Numerical calculation gives a cumulative function of tracer volume fraction $(\mathrm{F}(\mathrm{t}))$. With the help of eqns (1) and (2) the two results could be compared (Fig. 2). Tracer could be detected after a short time, which means that some particles could flow through the system rapidly. $E(t)$ increased until a certain time, showing the high intensity of exhaustion of tracer. After 18 hours, it began to decrease, while after four days some tracer still remained in the tank, representing the presence of dead-zones.

According to literature [15], after five days, 95\% of the tracer added could be measured in the samples. The details of this case study are described in Karches [16,17].

Average residence time was calculated using eqn (3). According to the numerical model, it was $45.3 \mathrm{~h}$ and according to the measurement it is slightly lower, i.e. $40 \mathrm{~h}$. While the V/Q ratio is $48.7 \mathrm{~h}$, where $\mathrm{V}$ is volume of the tank and $\mathrm{Q}$ is the hydraulic discharge. This result has two important consequences. First, the theoretical residence time calculated by the V/Q ratio is a very simple and misleading method. The differences between the estimated and real residence time could occur when the settling tanks do not operate well. RTD study contains the effect of small-scale phenomena, which may have a serious impact on the effluent wastewater quality. Second, the field measurement can be replaced by the three-dimensional RTD model because both have the same results, and we not only reduce the cost of the investigation but also save time. 


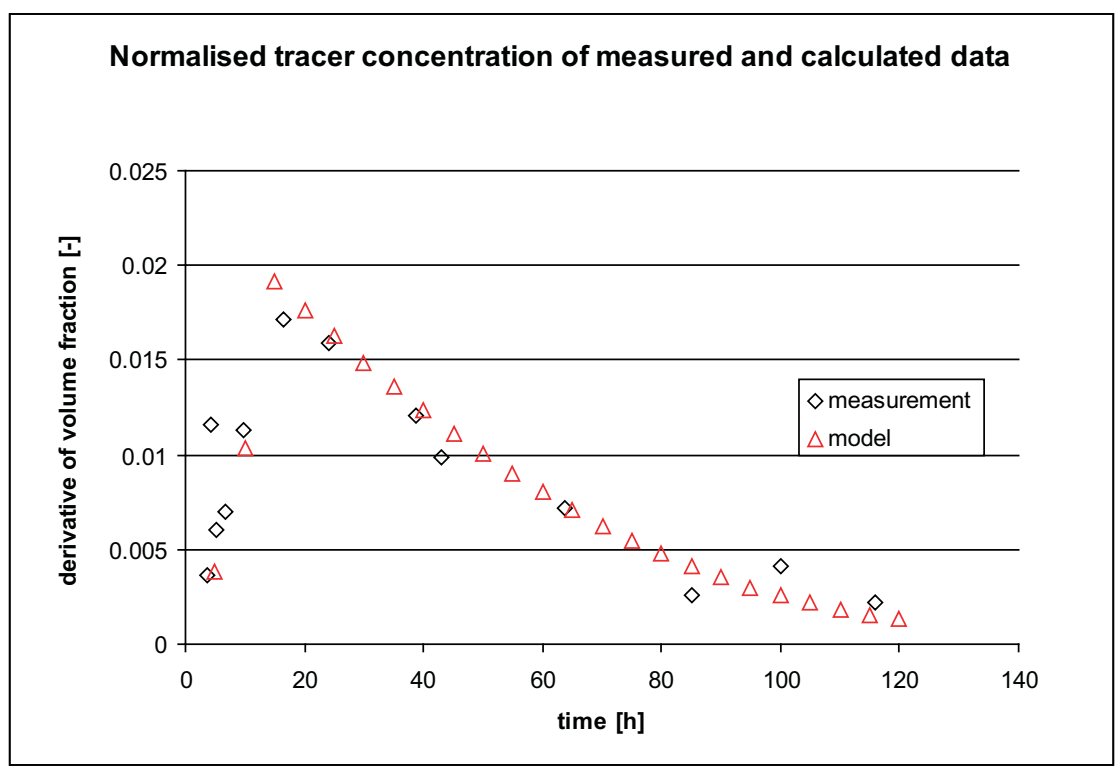

Figure 2: RTD study measured and calculated model response function of the injected tracer $\mathrm{E}(\mathrm{t})$.
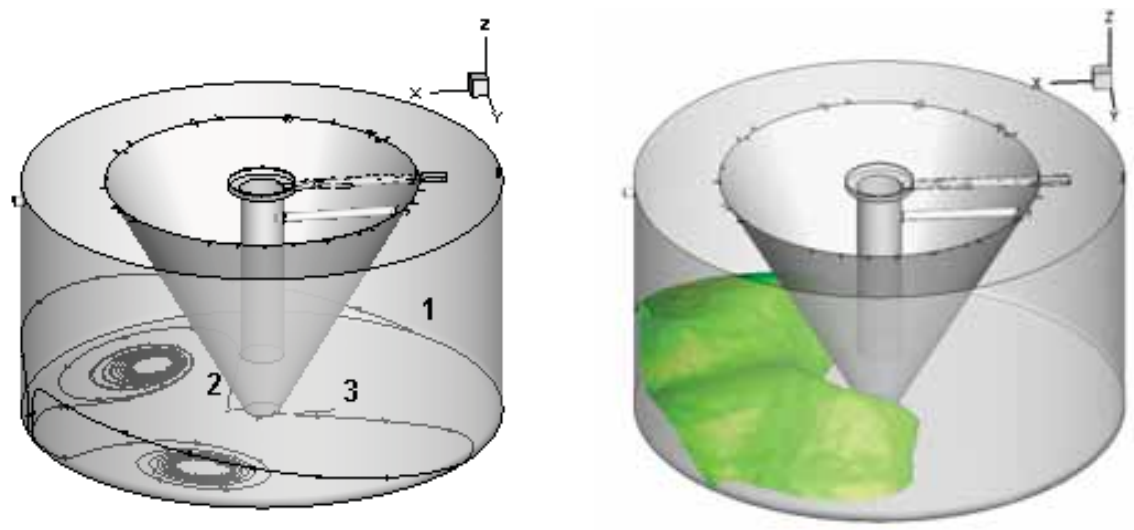

Figure 3: Wall streamlines shows the dead-zones (left). Isosurface of $50 \mathrm{~h} \mathrm{LMA} \mathrm{(right).}$

Three wall streamlines are displayed in Fig. 3, which demonstrates that the particles tend to flow towards two zones and they cannot escape. Here, dead-zones are attracting attention according to the flow topology classification [18] based on the eigenvalues of the rate-ofdeformation tensor [19]. Figure 3 also shows an isosurface of $50 \mathrm{~h}$ as LMA of the wastewater. Below the isosurface the mean age is larger and in the immediate vicinity of the critical point it can be more than $100 \mathrm{~h}$, while the theoretical average residence time is only $48 \mathrm{~h}$. 


\subsection{Sedimentation tank}

In the second case, a circular settling tank was examined at two different outflow conditions. The first has a traditional weir outflow, and the second has perforated tubes, which are under the surface by $25 \mathrm{~cm}$. The geometry of the tank is presented in Fig. 4. Both tanks have energy breakers at the inlet zone, which are responsible for diminishing of the velocity magnitude. Due to hydraulic reasons, the residence time is important in this case, which is $0.85 \mathrm{~h}$ theoretically, if we use $0.1 \mathrm{~m}^{3} / \mathrm{s}$ discharge of the wastewater. After the flow field is given, RTD study was carried out and LMA was calculated as described earlier and then the results were evaluated in both cases. The inlet boundary was mass flow inlet, and the outflow was open to atmosphere. Zero velocity was prescribed at the wall, and free surface condition was set at the top boundary.

The numerical tracer study revealed a significant difference between the two cases. The settling tank with weir outlet has a short-circuit because large volume fraction of the tracer appeared in a short period of time. Huge amounts of wastewater were able to flow through the system easily, and they did not have enough time for settling, thus resulting in poor effluent quality. Furthermore, the other part of the tracer remained in the tank for a long time. In the $\mathrm{E}(\mathrm{t})$ graph, the peak is due to the short-circuit and the slowly decreasing exponential part showed us that there is dead-zone (Fig. 5). Volume fraction distribution could have been observed, but it changed with time. In contrast, the LMA theory gives a steady-state solution for the fluid age. RTD in the second case, where perforated tubes were applied, shows a better agreement to the expected residence time. It may be surprising because by using perforated pipes, the average path of the wastewater is smaller than in the 'traditional' outlet; therefore, one could think that the fluid would leave the tank earlier. The explanation for this phenomenon is in the different flow field characteristics. Due to the pipes, the geometry changed and dead-zones could not develop. Using eqn (3), the settling tank with weir outlet has an average residence time of $1250 \mathrm{~s}$, while that for one of the settling tanks with perforated pipe outlet is $2200 \mathrm{~s}$. In the first case, the value is far from the expected value (3000 s), while in the second case, it is closer to the reality. The explanation can be found using LMA theory.

LMA was calculated in both cases. To avoid numerical errors, second order upwind scheme was used with a reduced 0.1 under-relaxation factor. Figures 6 and 7 show the results.

In both cases, the average residence time is lower than the expected value because of the short-circuit caused by the ineffective inflow design. The breakage of energy is not sufficient, and it is visible, especially in the first case, where the flow goes to the top. However, the other part of fluid goes towards the bottom. Here, the settled and scraped sludge can be active in movement again. In the first case, where weir outlets were used (See tank geometry in Fig. 4a),
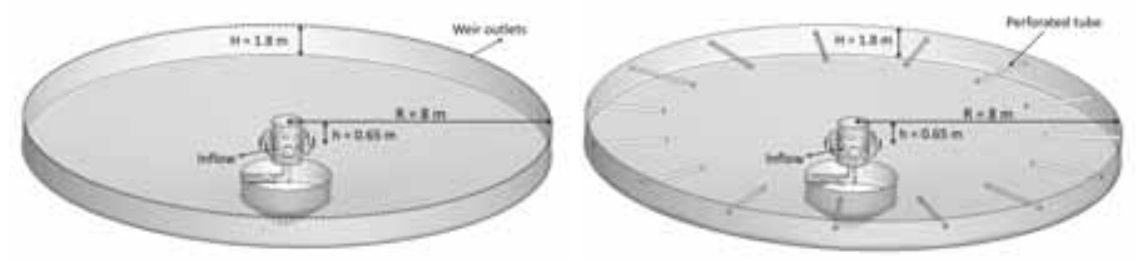

Figure 4: Geometry of circular settling tank with weir outlet (4.a, left) and perforated tube outlets (4.b, right). 


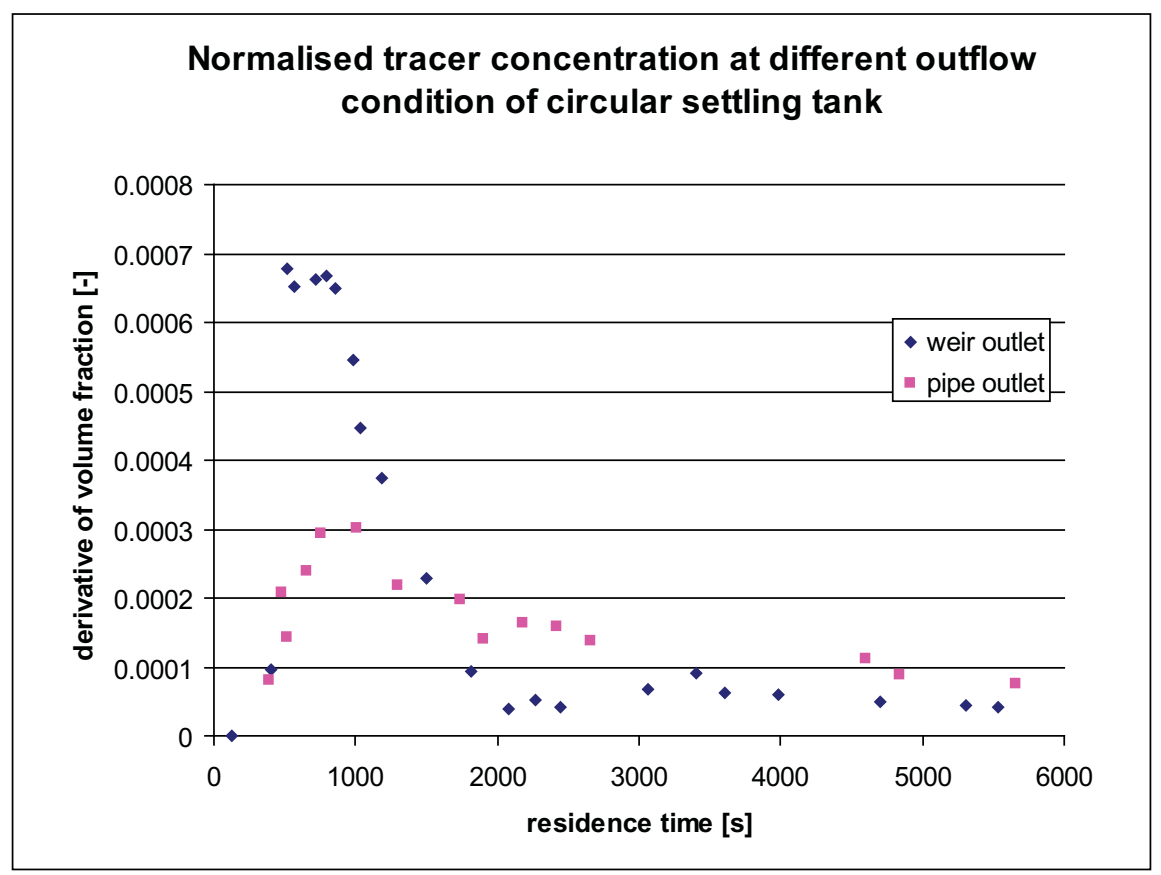

Figure 5: Normalized tracer concentration at different outflow condition (weir and perforated pipe outlet).

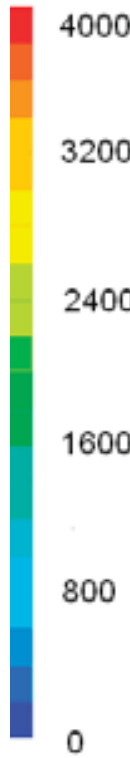

Figure 6: LMA in the circular settling tank with weir outlet, a cross section and a top view. LMA is in second. 


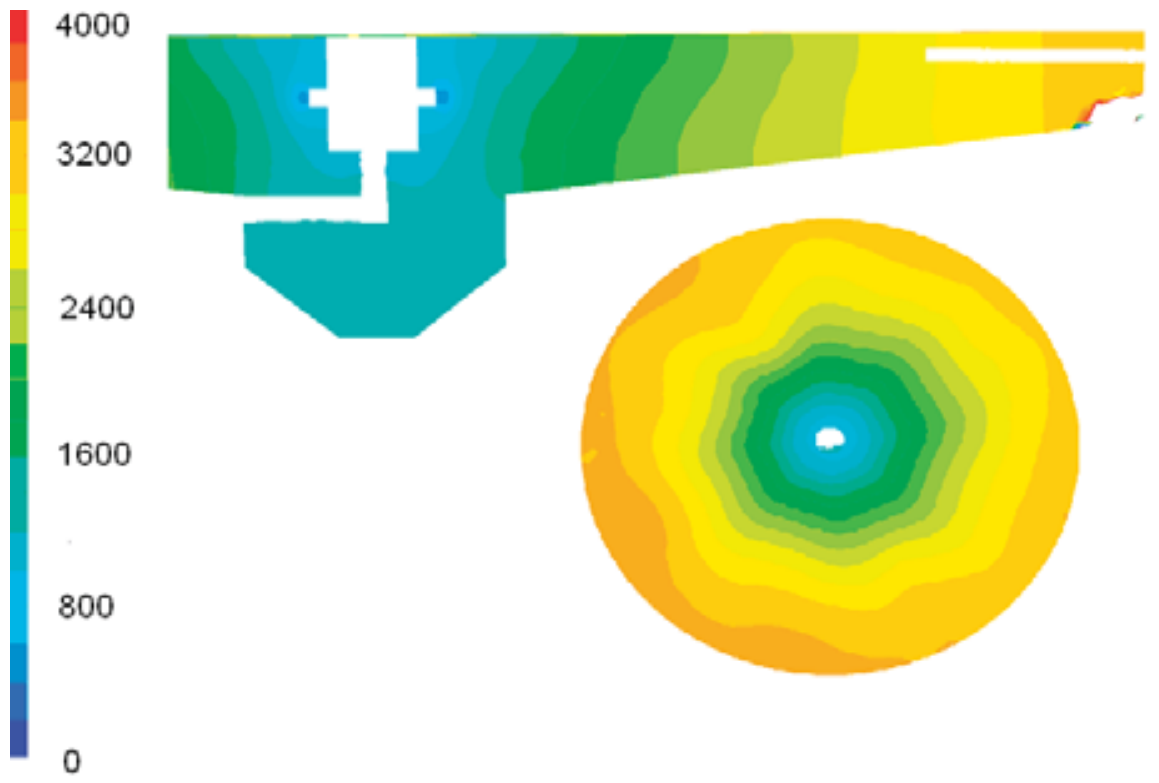

Figure 7: LMA in the circular settling tank with perforated tube outlet, a cross section and a top view. LMA is in second.

the relative high-speed fluid particles at the top form a jet, have small residence time, do not mix with the neighbouring zones and easily find the way out from the tank. Among the jets, dead-zones appeared (red colour on Fig. 6), and therefore the effluent through the weir was not uniform. This is also corresponds with RTD results. The smoothness of the flow was much better when perforated pipes were used. The flow field changed because previously appeared dead-zones were broken by the flow paths in order to reach the outlet. Small deadzones appeared at the bottom below the tubes, but the size was much smaller than in the previous case. Now we are closer to the expected residence time value, but further achievement could have been gained if the inlet water had been uniformly distributed. The aim of this paper was not to design a settling tank in detail, but show some techniques to determine deadzones and short-circuits.

\section{CONLUSION}

In some cases, dead-zones and short-circuits may be the reasons for poor performance of settling tanks and aeration tanks in wastewater treatment. The detection of small-scale phenomena became easier with the help of computational fluid dynamics, but the validation of the flow field is still challenging for the engineers today. Modeling requires extensive knowledge on turbulent flow, multiphase systems and numerical approaches. If poor effluent quality cannot be derived from (bio)chemical processes directly, a tracer study is useful to reveal the hydraulics within the tank. It can be done experimentally and numerically, but this can be time consuming. We performed a tracer study, which gave us information about the real residence time. In order to look into the traditionally black box-handled settling tanks, LMA was calculated via a scalar transport equation. Numerical instabilities occurred, because there were high gradients in the fluid age distribution between the dead-zones and the neighbouring fluid zones. Finer mesh and reduced under-relaxation factors needed to be applied. Based 
on the eigenvalues of the rate-of-deformation tensor around critical points, the occurrence of dead-zones can also be predicted, which needs further investigations. Overall conclusion is that the RTD-LMA study corresponds well with field measurement data and is an effective tool to determine dead-zones and other small-scale phenomena in fluid flow.

\section{ACKNOWLEDGEMENTS}

This work is connected to the scientific programme of the "Development of qualityoriented and harmonized R+D+I strategy and functional model at BME" project. This project is supported by the New Széchenyi Plan (Project ID: TÁMOP-4.2.1/B-09/1/KMR-20100002).

\section{REFERENCES}

[1] ATV-DVWK Arbeitsblatt-A-131, GFA, Hennef, 2000.

[2] Greenfield, P.F., Howes, T., Johns, M.R., Keller, J. \& Wood, M.G., Computational fluid dynamic modelling of wastewater ponds to improve design. Water Science and Technology, 31(12), pp. 111-118, 1995. doi: http://dx.doi.org/10.1016/0273-1223(95)00498-C

[3] Brouckaert, C.J. \& Buckley, C.A., The use of computational fluid dynamics for improving the design and operation of water and wastewater treatment plants. Water Science and Technology, 40(4-5), pp. 81-90, 1999. doi: http://dx.doi.org/10.1016/ $\underline{\text { S0273-1223(99)00488-6 }}$

[4] Bartrand, T.A., Farouk, B., Greene, D.J., Haas, C.N., Liberti, L., Notarnicola, M. \& Santoro, D., Use of CFD for wastewater disinfection process analysis: E.coli inactivation with peroxyacetic acid (PAA). International Journal of Chemical Reactor Engineering, 3(46), pp. 1283-1287, 2005.

[5] Gentric, C., Leclerc, J.P., Moullec, Y.L. \& Potier, O., Flow field and residence time distribution simulation of a cross-flow gas-liquid wastewater treatment reactor using CFD. Chemical Engineering Science, 63, pp. 2436-2449, 2008. doi: http://dx.doi. org/10.1016/j.ces.2008.01.029

[6] Burt, D.J. \& Ganeshalingam, J., Design and optimisation of final clarifier performance with CFD modelling. CIWEM conference Design and operation of activated sludge plants, 2005.

[7] Armbruster, M., Krebs P. \& Rodi, W., Numerical modelling of dynamic sludge blanket behaviour in secondary clarifiers. Water Science and Technology, 43(11), pp. 173-180, 2001.

[8] Patziger, M., Kainz, H., Hunze, M. \& Józsa, J., Analysing sludge balance in activated sludge systems with a novel mass transport model. Water Science and Technology, 57(9), pp. 1413-1419, 2008. doi: http://dx.doi.org/10.2166/wst.2008.221

[9] Foias, C., Manley, O., Rosa, R. \& Temam, R., Navier-Stokes Equations and Turbulence, Cambridge Books Online, Cambridge, pp. 1-3, 2001. doi: http://dx.doi.org/10.1017/ CBO9780511546754.002

[10] Launder, B.E. \& Spalding, D.B., The numerical computation of turbulent flow. Computer Methods in Applied Mechanics and Engineering, 3(2), pp. 269-289, 1974. doi: http://dx.doi.org/10.1016/0045-7825(74)90029-2

[11] Fluent 6.3 Users Guide. Ansys Inc., USA.

[12] Manninen, M., Taivassalo, V. \& Kallio, S. On the Mixture Model for Multiphase Flow. VTT Publications 288, Technical Research Centre of Finland, 1996. 
[13] Kurasinski, T. \& Kuncewicz, Cz., Determination of turbulent diffusion coefficient in an agitator for special type of impeller. 3th European Conference on Mixing, London, 2009.

[14] Chanteloup, V. \& Mirade, P.-S., Computational fluid dynamics (CFD) modelling of local mean age of air distribution in forced-ventilation food plants. Journal of Food Engineering,90,pp.90-103,2009.doi: http://dx.doi.org/10.1016/j.jfoodeng.2008.06.014

[15] Buttz, J.A. \& Daigger, G.T., Upgrading Wastewater Treatment Plants, Technomic Pub Co.: Lancaster, PA, Vol. 2, pp. 13-53, 1998.

[16] Karches, T. \& Buzas, K. Methodology to determine residence time distribution and small scale phenomena in settling tanks. Computational Methods in Multiphase Flow VI. WIT Transactions on Engineering Sciences, 70, pp. 117-126, 2011. doi: http:// dx.doi.org/10.2495/MPF110101

[17] Karches, T. \& Melicz, Z., Problem detection in a small wastewater treatment tank with the tool of computational fluid dynamics. 9th international Congress on Advances in Civil Engineering, KTU,Trabzon, Turkey, 2010.

[18] Laramee, R.S., Hauser, H., Zhao, L. \& Post, F.H., Topology-based flow visualization. The state of the Art. Proceedings of Topo-In-Vis, Budmerice, Slovakia, 2005.

[19] Chong, M.S., Perry, A.E. \& Cantwell, B.J., A general classification of threedimensional flow fields. Phys Fluids A, 2(5), pp. 765-778, 1990. doi: http://dx.doi.org/ $\underline{10.1063 / 1.857730}$ 